\title{
AN OPEN LABELLED RANDOMIZED CLINICAL TRIAL OF FLUOXETINE VERSUS DAPOXETINE TREATMENT AMONG MEN WITH PREMATURE EJACULATION AND ITS EFFECT ON MARITAL SATISFACTION
}

\author{
Mohammad Che Man ${ }^{1}$, Faridah Mohd Zain², Najib Majdi Yaacob ${ }^{3}$, Shahidah Che Alhadi \\ and Shaiful Bahri Ismail ${ }^{2}$ \\ ${ }^{1}$ Department of Family Medicine, Kulliyyah of Medicine, International Islamic \\ University Malaysia, Indera Mahkota, Pahang, Malaysia, ${ }^{2}$ Department of Family \\ Medicine, School of Medical Sciences, Universiti Sains Malaysia, Kubang Kerian, \\ Kelantan, Malaysia, ${ }^{3}$ Biostatistic Unit, School of Medical Sciences, Universiti Sains \\ Malaysia, Kubang Kerian, Kelantan, Malaysia, ${ }^{4}$ Department of Surgery, Kulliyyah of \\ Medicine, International Islamic University Malaysia, Indera Mahkota, Pahang, \\ Malaysia.
}

Presenter: Mohammad Bin Che Man, mohdcheman@iium.edu.my

Introduction: Premature ejaculation (PE) reduces sexual satisfaction and quality of life. Both SSRI Fluoxetine and Dapoxetine have been used in the treatment of PE. Fluoxetine is used as off-label treatment meanwhile Dapoxetine is the first SSRI specifically designed for PE with short half-life and few side effects.

Objectives: To compare the PE symptoms and marital satisfaction score between Fluoxetine and Dapoxetine groups.

Materials and method: In this clinical trial, 44 participants aged between 18 and 64 with PEDT score of $\geq 9$ from the Primary Care clinic of Hospital USM, Kelantan were recruited and randomized into two groups; Fluoxetine Group(FG) and Dapoxetine Group(DG). They were prescribed with either daily oral Fluoxetine $20 \mathrm{mg}$ or Dapoxetine $30 \mathrm{mg}$ on demand twice weekly for 8 weeks. PE symptoms were measured using the Premature Ejaculation Diagnostics Tool(PEDT) score and marital satisfaction score were measured using the Dyadic Satisfaction-Dyadic Adjustment Scale(DS-DAS) score. Measurements were made at baseline and at the $8^{\text {th }}$ week(post intervention).

Results: In FG and DG, 22 and 21 participants completed the study, respectively. PEDT scores reduced significantly within both groups[from 11.41 to $5.45(P<0.001)$ within FG and from 13.43 to $3.10(P<0.001)$ within the $D G]$. At the $8^{\text {th }}$ week follow-up, PEDT scores was observed to be were lower in $D G(6.03$ vs. $2.49, P<0.001)$ after adjustment of the baseline PEDT score. Significantly increased DS-DAS scores were observed in both groups [from 34.50 to $40.68(P<0.001)$ within $F G$ and from 36.57 to $44.33,(P<0.001)$ within $D G$ ] with no significant difference in DS-DAS scores at the end of study(41.13 vs. 43.86, $\mathrm{P}=0.055$ ) after adjustment of the baseline DS-DAS score.

Conclusion: Reduction in PE symptoms was observed for both groups. At 8 weeks, PE symptoms among participants on Dapoxetine were significantly lower compared to the participants on Fluoxetine at 8 weeks. Treatment of PE with either Fluoxetine or Dapoxetine reduces symptoms of PE and improves marital satisfaction. 